\title{
Features of the reproductive system development in the installations of closed water supply system
}

\author{
Elena Ponomareva ${ }^{1,{ }^{*}, \text { Peter Geraskin }}{ }^{2}$, Marina Sorokina $^{1}$, Angelika Kovaleva ${ }^{1}$, and Vadim \\ Grigoriev $^{1}$ \\ ${ }^{1}$ Federal Research Centre The Southern Scientific Centre of the Russian Academy of Sciences, 41, \\ Chekhov str., 344006, Rostov-on-Don, Russia \\ ${ }^{2}$ Astrakhan State Technical University, 16, Tatishchev St., 414056, Astrakhan, Russia
}

\begin{abstract}
The paper considers the functional changes in the reproductive function of sturgeon species of different ages and their hybrids. The dynamics of the development of gonads of females and males during the reproductive cycle is studied. According to the results of studies, it is shown that when the hydrological and hydrochemical regimes of cultivation are stabilized, spawning intervals are reduced, as well as the time of maturity. In this case, the physiological and biochemical status of females at the final stages of maturity is normal, which is confirmed by research results. The development of oocytes in females raised under regulated conditions takes place without any deviations.
\end{abstract}

\section{Introduction}

In recent years, the influence of various forms of human economic activity on the natural nature has increased, which leads to deep negative changes. These changes are significant, lasting, and often irreversible. The reduction of spawning populations, the reduction of natural spawning grounds and the replenishment of sturgeon from natural spawning put sturgeon on the brink of extinction. In this situation, conservation of stocks is one of the essential measures used to increase natural populations [1]. However, sturgeons are characterized by a long life cycle, late maturity and lack of synchronization of puberty, which makes it difficult to obtain offspring [2]. Therefore, the cultivation of sturgeons requires a detailed understanding of the specifics of the reproductive process, the influence of various factors on the characteristics of each stage of puberty, as well as the body's requirements for the conditions at different stages of development. To the greatest extent, this is true for fish breeding enterprises that grow sturgeon under conditions of altered temperature conditions (ultrasound, complexes in warm waters, etc.). In recent years, aquaculture recirculation systems have attracted increasing interest as a means to intensify fish production and at the same time minimize environmental impact [3].

In recent years in various countries, considerable practical experience has been accumulated in the design, construction and operation of intensive plants for various types.

\footnotetext{
* Corresponding author: kafavb@mail.ru
} 
Thus, the successful production of aquaculture facilities in ultrasonic testing is largely limited to identifying the biological needs of these species and developing intensive aquaculture facilities with the necessary environmental parameters. The formation of brood stocks and the generation of offspring from them is a prerequisite for the successful production of species in closed water supply plants. Intensive recirculation plants have significant potential, as they can significantly reduce water consumption and the concentration of nutrients needed by cultivated objects, due to continuous technological developments. When used for growing aquaculture objects, the following parameters of the aquatic environment can be controlled: temperature, dissolved oxygen, carbon dioxide, ammonia, nitrites, nitrates, $\mathrm{pH}$, salinity and suspended solids. This allows one to maintain growing conditions for optimal growth of the species, as well as diversify the species that can be cultivated in these systems, which is a prerequisite for ensuring sustainable development of the industry [3].

Maturation of sturgeon under various conditions of artificial cultivation was studied by many researchers [4-7]. The dynamics of the development of germ cells in the gonads is a long and complex process, the normal course of which depends on a number of external and internal factors [8]. So, abiotic and biotic factors, closely related to each other and partly due to the anthropogenic influence of the external environment, can be of decisive importance. Moreover, age-related features, the role of the thermal regime and the provision of feed are extremely significant, as a result of which the development of germ cells can accelerate, slow down, or even stop [9].

The main problems that have to be overcome when breeding sturgeon in aquaculture are related to species-specific features of their reproductive biology [10]. One problem is the late age when they reach puberty. For example, it takes 5-6 years for a male Siberian sturgeon to reach maturity in captivity, which is much less than in the wild $[11,12]$.

It was noted that with different methods of growing and using different methods of intensification of the fish breeding process, it is possible to shorten the ripening of hybrid forms of sturgeon species of fish and obtain first-ripening males at the age of 2.5-3.5 years, females at the age of 3.5-4 years. One of the mechanisms for controlling the reproductive system of fish in artificial fish farming is the regulation of the timing of achieving puberty, changing the duration of the early phases of the development of germ cells and the frequency of spawning $[13,14]$.

The objective of our research was a comparative analysis of the development of the reproductive system, the study of the maturation and inter-spawning periods of various types of sturgeons and their hybrids when grown in ultrasonic testing.

\section{Material and research methods}

The studies were conducted at the Southern Scientific Center of the Russian Academy of Sciences. The object of the study was manufacturers of sterlet (Acipenser ruthenus Linnaeus, 1758) in the amount of 63 specimens, sterlet $\times$ beluga hybrid (Acipenser ruthenus Linnaeus, $1758 \times$ Huso huso Linnaeus, 1758) in the amount of 85 specimens, Russian sturgeon (Acipenser gueldenstaedtii Brant 1833), in the amount of 50 specimens, the hybrid Russian sturgeon-Lena sturgeon (Acipenser gueldenstaedtii Brant et Ratzeburg, $1833 \times$ Acipenser baerii Brandt, 1869) (hereinafter the Russian-Lena sturgeon) in the amount of 65 specimens grown in the aquacomplex of the Southern Scientific Center of the Russian Academy of Sciences . The experiments were carried out in a closed water supply (CWS) with year-round adjustable water regime. Fish was grown in pools $3 \times 5 \mathrm{~m}, 2 \times 2 \mathrm{~m}$ and $1 \times 1 \mathrm{~m}$ in size. The temperature regime was stable $-21.0-22.0^{\circ} \mathrm{C}$, oxygen saturation of the water was $72-87 \%$, and $\mathrm{pH}$ was $7.0-7.5$, which is optimal for the studied objects. Feeding was carried out with artificial feed according to the calculated norms [5]. Daily 
water renewal in the system did not exceed $5 \%$ of its total volume. The study of sex and determination of the stages of maturity of fish was carried out using an ultrasonic scanner Sono Scape. Recognition was carried out by differences in the shape and echogenicity of the ovaries and testes. After an ultrasound scan using a semi-automatic biopsy system and a fish probe, gonads were taken for microscopic analysis using a Saikedigital microscope and determination of the polarization coefficient of oocytes [5].

The duration of fish maturation under various conditions is determined by the heat reserve, which characterizes the thermal regime of the period when the average daily temperatures exceed the biological minimum temperature necessary for the development of the body. The heat reserve was determined as the sum of the average daily temperatures during the ripening period of the fish and expressed in degree-days.

\section{Results and discussion}

The reproductive system of a sterlet and a its hybrid with beluga at the age of 2 years was studied. The analysis of sterlet gonadogenesis revealed that $39.7 \%$ of 63 individuals are males and $60.3 \%$ are females, while the hybrid has a male share of $29.8 \%$ and a female share of $70.2 \%$. It was revealed that at the age of 26 months, males were at the II, III, IV stages of maturity. For example, the largest percentage of sterlet was found in individuals of the second and third stages of maturity, respectively 37 and $42 \%$ (Fig. 1), the smaller part $(21 \%)$ were males who reached the IV stage of sexual gonad maturity. In males of the sterlet $\times$ beluga hybrid, the gonads were represented in $35 \%$ of the II-th and $55 \%$ of the IIIth stage of maturity. The number of mature males reached $10 \%$, according to figure 1.

Oocytes of $73 \%$ of female sterlet were at stage II of maturity, $27 \%$ - at stage III. Similar results were obtained in the study of female gonads of the sturgeon $\times$ beluga hybrid. Thus, $86 \%$ and $14 \%$ of females did not reach the final stages of gonad development and were at the II and III stages of maturity, respectively (Fig. 1). In the study of biopsy material, it is recommended to use indicators of the oocyte polarization coefficient as a preliminary criterion for selecting mature females. Thus, females with oocytes with a polarization coefficient of at least 15-18 have a chance to mature in a few months. Six months later, we re-tested the individuals of the sterlet and the hybrid sterlet $\times$ beluga to determine the degree of maturity. The results showed that $70.3 \%$ of the females of the examined groups and $90.2 \%$ of the males were mature, and their reproductive cells were at the IV stage of maturity.

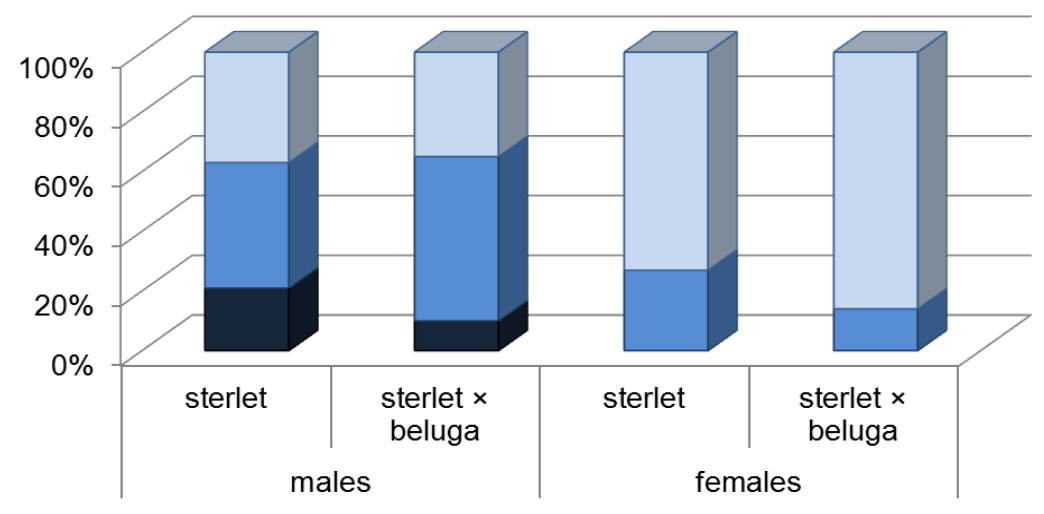

口Il gonad maturity stage ㄴIII gonad maturity stage $\quad$ IV gonad maturity stage

Fig. 1. Ratio of male and female sterlet and hybrid sterlet $\times$ beluga by stages of gonads' maturity at the age of 26 months. 
In the study of the sex of Russian sturgeon breeders at the age of 39 months, $42.6 \%$ were identified as males, $51.4 \%$ as females with sexual products at various stages of maturity. It was not possible to determine the gender of three individuals. In the study group of Russian-Lena sturgeon, it was determined that the number of females is $53 \%$, and males- $47 \%$. In the group of Russian sturgeon males, it was found that $35 \%$ of individuals were at the II stage of gonad maturity, $65 \%$ - at the III stage. Russian-Lena sturgeon males, unlike Russian sturgeon ones, matured more actively, so that $12 \%$ of individuals were at the final stages of maturity. Fish with immature gonads corresponding to stages II and III were represented by $88 \%$. The ovaries of both female species were at stages II and III of maturity (Fig. 2).

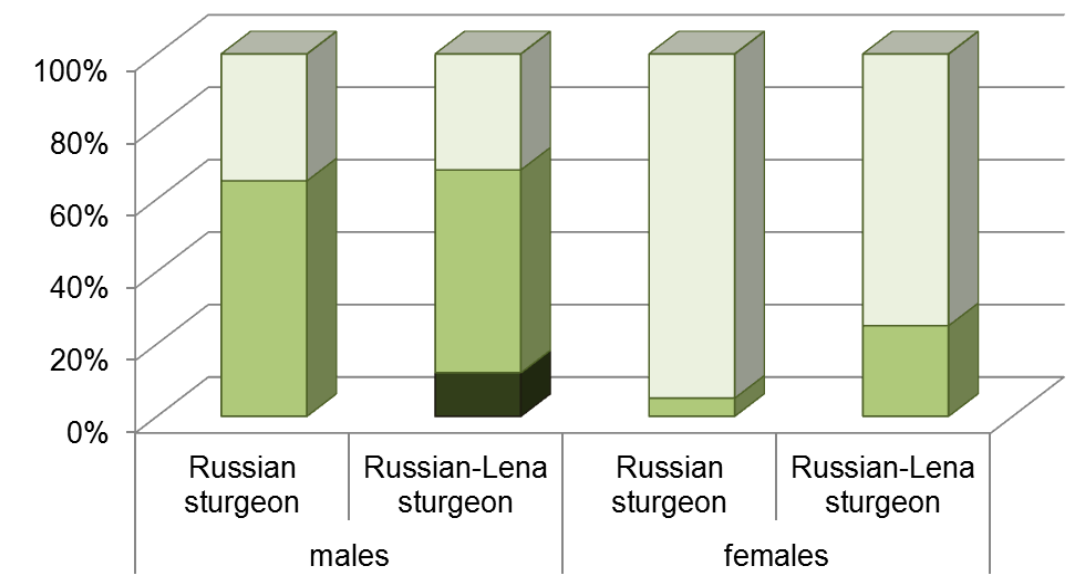

- IV gonad maturity stage ㅁIII gonad maturity stage ㅁII gonad maturity stage

Fig. 2. Russian and Russian-Lena sturgeon male-female ratio by gonads' maturity at the age of 39 months.

Russian sturgeon and Russian-Lena sturgeon breeders repeated testing after 16 months (age 4.5 years) showed that during this period of time, ovaries and testes reached the IV-th completed stage of maturity. During this period there was a completion of oogenesis and spermatogenesis.

Figure 3 shows oocytes at various stages of gonad development. The development of reproductive cells occurs in accordance with the biological characteristics of sturgeon species.

Figure 3A shows samples of generative tissue with oocytes in the stage of trophoplasmic growth. At this stage of development, the gonad contains a sufficient amount of adipose tissue necessary for the energy supply of oocyte growth.

In figure $3 \mathrm{~B}, \mathrm{C}, \mathrm{D}$ - oocytes at the III and IV stages of gonad maturity, with clearly formed holozoic and vegetative poles, which indicates the normal completion of gametogenesis and full maturation of female sturgeon. 


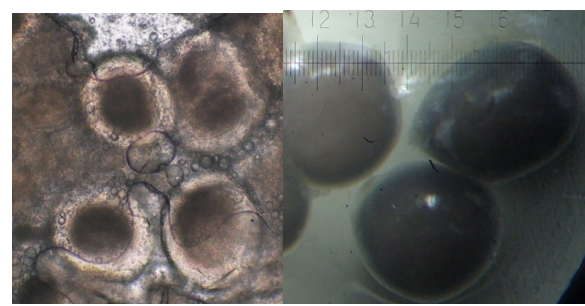

A

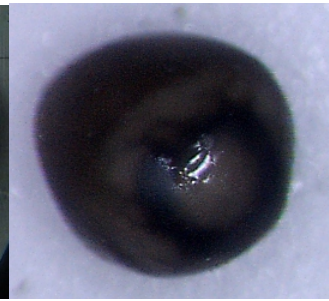

C

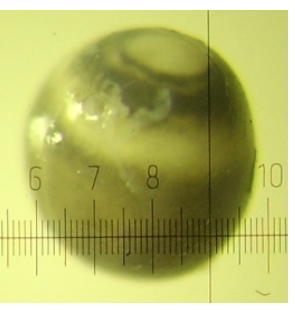

D

Fig. 3. Sturgeon oocytes at different stages of development: A - oocytes at the II stage of maturity, the beginning of the growth period; B - oocytes at the III stage of maturity; C - oocyte at the IV incomplete stage of maturity; D - oocyte at the IV completed stage of maturity.

As a result of the research, it was found that it took 15125 degree-days for the male sterlet contained in the thermal regime of $21-22{ }^{\circ} \mathrm{C}$ to mature (the age of the first matured individuals is 23.5 months.). The maturation period of females is significantly longer than 200 degree - days (31.3 months). Males of the sterlet $\times$ beluga hybrid reach sexual maturity at 25 months with the sum of effective temperatures of 16125 degree-days, females-at 33.9 months when the amount of heat is 21850 degree-days. The value of inter-spawning intervals in the sterlet and hybrid was 3300 and 4200 degree-days, respectively.

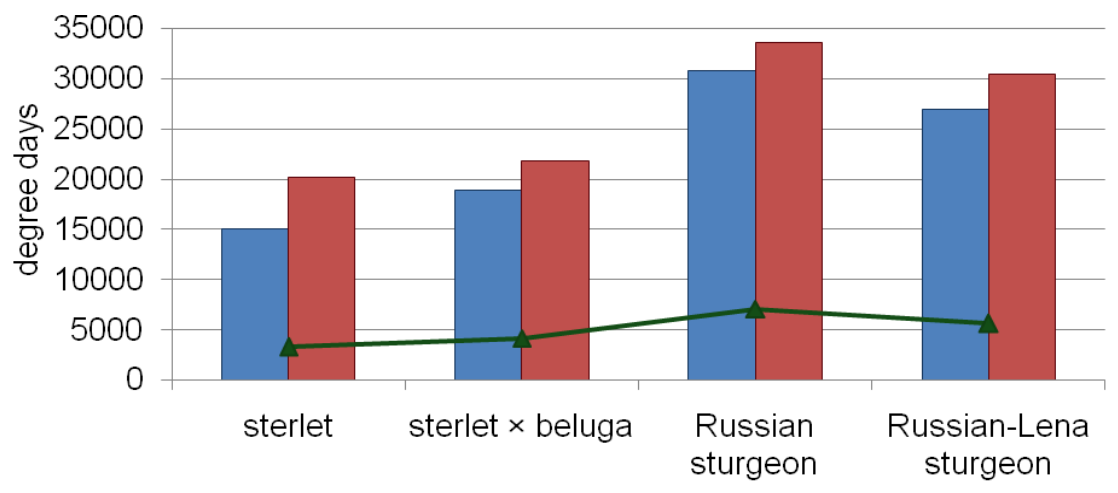

$\square$ males $\square$ females $\rightarrow$ Duration of inter-spawning intervals, degree-days

Fig. 4. Necessary heat reserve for sturgeon maturation and duration of inter-spawning periods.

Stabilization of the temperature regime allowed to obtain male and female of Russian sturgeon with reproductive cells at the IV stage of maturity with the amount of heat of 30800 and 33650 degree- days, the age of the first mature individuals is 47.8 and 52.2 months, respectively. Russian- Lena sturgeon has a spawning interval of 5650 degree-days, while Russian sturgeon has more than 1450 degree-days.

The maturation of sturgeon when growing modes are stabilized depends largely on the temperature of the water environment, which affects all functionally important fish systems. Under natural temperature conditions, there is a significant lengthening of reproductive cycles, and when the temperature drops below the minimum possible for growth values, the processes of both protoplasmic and trophoplasmic growth of oocytes are stopped, accompanied by the use of part of the energy substances accumulated in the gonads to ensure the vital activity of the body [15]. Thus, under natural temperatures of warm-water farms, Russian sturgeon males become sexually mature at the age of 3-4 years, and females-at the age of 6-7 years. The sterlet males mature at an earlier date, in 2-3 years, females at 3-4 years. The optimal water temperature for spawning breeders is $13-16{ }^{\circ} \mathrm{C}$ [16]. 
In systems with a controlled temperature regime, the duration of reproductive cycles can be reduced by optimizing the conditions of fish stocking [15]. The terms of the first maturation of sturgeon breeders in the conditions of RAS in comparison with warm water and pond farms in the V, VI zones of fish farming are reduced by $40 \%$, and the interspawning interval is reduced by $50 \%$ [17]. However, when growing at consistently high water temperatures $\left(21-22^{\circ} \mathrm{C}\right)$, short-term wintering at low temperatures is necessary to complete the gametogenesis process in sturgeon fish and the transition of oocytes to the IV completed stage of maturity $[5,18,19]$, which contributes to the synchronicity of cell development in individuals, which, in turn, confirms the normal course of generative processes in these fish.

In the study of some physiological indicators, no functional disorders were detected in fish kept in regulated conditions (table 1).

Table 1. Some physiological and biochemical indicators of breeders when growing in the conditions of RAS.

\begin{tabular}{|c|c|c|c|c|}
\hline Indicators & $\begin{array}{c}\text { Hemoglobin. g } \\
\text { / I }\end{array}$ & $\begin{array}{c}\text { Erythrocyte } \\
\text { sedimentation } \\
\text { rate. mm / h }\end{array}$ & $\begin{array}{c}\text { Total serum } \\
\text { protein. g / I }\end{array}$ & $\begin{array}{c}\text { Cholesterol. } \\
\text { mmol / I }\end{array}$ \\
\hline \multicolumn{5}{|c|}{ Hybrid sterlet x beluga } \\
\hline $\mathrm{M} \pm \mathrm{m}$ & $81.7 \pm 1.87$ & $3.83 \pm 0.78$ & $36.95 \pm 1.37$ & $3.78 \pm 0.39$ \\
\hline$\sigma$ & 4.59 & 1.91 & 3.35 & 0.95 \\
\hline $\mathrm{CV} \%$ & 5.62 & 49.95 & 9.07 & 25.04 \\
\hline \multicolumn{5}{|c|}{ Sterlet } \\
\hline $\mathrm{M} \pm \mathrm{m}$ & $97.5 \pm 19.5$ & $4.5 \pm 2.5$ & $38.15 \pm 1.75$ & $3.5 \pm 0.7$ \\
\hline$\sigma$ & 27.58 & 3.54 & 2.47 & 0.99 \\
\hline $\mathrm{CV} \%$ & 28.28 & 78.57 & 6.49 & 28.28 \\
\hline
\end{tabular}

The values of erythrocyte sedimentation rate and total serum protein were in the previously established ranges of variability for sturgeon during maturation $-2.0-4.0 \mathrm{~mm} / \mathrm{h}$ and $28.0-40.0 \mathrm{~g} / 1$, respectively $[20,21]$. Hemoglobin, as an indicator of the activity of metabolic processes in the body, in the blood of sturgeon varies between 50.0-80.0 g/l. However, during the growth of oocytes, its concentration in the blood increases, as evidenced by the data obtained, which noted that the value of this indicator was slightly increased 81.7-97.5 g/l. A decrease in the hemoglobin content in the active phase of formation of sexual products indicates a violation of generative exchange, and an increase in the content after the winter period is associated with the need for additional energy for the final completion of the gonad formation process [20,21]. The cholesterol content in both species was at the level of 3.5-3.78 mmol / 1. the Total range of cholesterol variability in sturgeon was $1.0-2.8 \mathrm{mmol} / \mathrm{l}$. In natural breeders during spawning migration, its concentration in blood serum increased from 1.87 to $4.45 \mathrm{mmol} / 1$. after the winter break, the cholesterol content increases from $2.80 \pm 0.20$ to $4.11 \pm 0.21 \mathrm{mmol} / \mathrm{l}$, which is associated with active utilization of lipid reserves and the final completion of the process of gonad formation in fish contained in the RAS [21].

In the study of the development of the reproductive system of females and males of various species of sturgeon and their hybrids, some features of the dynamics of gonad development were revealed. Thus, females and males of the Russian-Lena sturgeon have a steady advance in gonad development during all the main stages of gonadogenesis. Mature breeders at the age of 39 months were not observed in the Russian sturgeon, in contrast to its interspecific hybrid with the Lena sturgeon, which by this time had already matured part of the males $(12 \%)$. Females also had accelerated gonad development, and females who reached the third stage of maturity had a $20 \%$ increase. 
These features are primarily related to the species belonging of the parent hybrid individuals, namely the Siberian sturgeon of the Lena population, which, when grown under stable temperatures, matures at an earlier time, compared with the Russian sturgeon.

In the case of the sterlet-beluga hybrid, the maturation rate is inherited from the sterlet, and the mass accumulation intensity is inherited from the beluga. So, mature males at the age of 26 months were 2 times more than the hybrid form. The same trend was observed in females - the proportion of female sterlet that reached the III stage of maturity is 2 times higher.

Studies of the development and formation of gonads during the passage of annual cycles in sturgeon show that changes in the temperature conditions of females in the pre-spawning period change the rhythm of reproduction, development and formation of gonads. There are noticeable changes in the duration of the resorption process, the growth of oogonies, and the periods of protoplasmic and trophoplasmic growth [22]. In the natural habitat, sterlet breeders are characterized by an inter-spawning interval, which is from 2 to 3 years in males, and from 3 to 4 years in females. In artificial conditions, this interval is significantly reduced from 1 to 2 years, and in the conditions of ultrasound it can be less than one year [5]. The minimum inter-spawning interval of female hybrid between Russian and Lena sturgeon in a warm-water garden economy is two years. Taking into account the need for this hybrid to set about 9000 degree -days between two consecutive spawns, the average inter-spawning interval (excluding wintering for 2-3 months) should be approximately 1.3 years. Males of the hybrid usually mature annually under the conditions of the RAS [23]. The inter-spawning interval in Russian sturgeon female under artificial cultivation lasts 1-3 years [18]. The terms of inter-spawning intervals of the Russian sturgeon and its hybrid form were reduced to less than a year.

In conclusion, it should be noted that the use of technological methods for growing sturgeon fish while stabilizing hydrological and hydrochemical regimes allows obtaining mature fish with a high reproductive status in a shorter time.

\section{Acknowledgements}

The publication was prepared as part of the implementation of the SA of the SSC RAS, no. 01201354245 using the USI "MUC " of the SSC RAS and the Bioresource collection of rare and endangered fish species of the SSC RAS No. 73602.

\section{References}

1. R.P. Khodorevskaya, V.A. Kalmykov, A.A. Zhilkin, Bulletin of the Astrakhan state technical University. Series: fisheries 1, 99-106 (2012)

2. H. Du, X. Zhang, X. Leng, S. Zhang, J. Luo, Z. Liu, X. Qiao, B. Kynard, Q. Wei, General and Comparative Endocrinology 245, 36-43 (2017)

3. N.R. Le François, M. Jobling, C. Carter, P. Blier, Finfish Aquaculture Diversification, CABI, 61-87 (2010)

4. L.M. Vasilieva, Technologies of food and processing industry of agro-industrial complex-healthy food products 1, 18-23 (2015)

5. G.G. Matishov, E. N. Ponomareva, N. G. Zhuravleva, and others, Practical aquaculture (Publishing house of the UNC RAS, Rostov n/A, 2011)

6. E.N. Ponomareva, A.V. Kovaleva, M.N. Sorokina, A.A. Korchunov, Natural Sciences 4(33), 68-74 (2010) 
7. G.G. Matishov, A.A. Kokoza, G.F. Metallov, P.P. Geraskin, Comprehensive approach to the problem of conservation and reproduction of sturgeon fish of the Caspian sea (Publishing house of the SSC RAS, Rostov n/D, 2017)

8. M.S. Koziy, I.M. Sherman, Questions of the Belarusian fisheries: the Republican subsidiary of the unitary enterprise "Institute of fisheries" of the Republican unitary enterprise "Scientific and practical center of the National Academy of Sciences of Belarus on animal husbandry"(Minsk) 26, 50-56 (2010)

9. G.F. Metallov, E.N. Ponomareva, P.P.Geraskin, V.A. Grigoriev, O.A. Levina, Bulletin of the Astrakhan state technical University. Ser.: Fisheries 2, 57-68 (2015)

10. O.P. Filippova, I.A. Burtsev, A.S. Safronov and others, Proceedings of VNIRO 148, 170-179 (2010)

11. Report of the FAO Food and Agriculture Organization for fisheries and aquaculture for 2012 (2012)

12. J. Dalsgaard, I. Lund, R. Thorarinsdottir, A. Drengstigc, K. Arvonend, P. Bovbjerg Pedersen, Aquacultural Engineering 53, 2-13 doi.org/10.1016/j.aquaeng.2012.11.008

13. M.I. Shatunovsky, G.I. Ruban, Actual problems of modern ichthyology (for the 100th anniversary of G.V. Nikolsky) (2010)

14. E.N. Ponomareva, M.N. Sorokina, V.A. Grigoriev, A.V. Kovaleva, A.A. Korchunov, Bulletin of the Astrakhan state technical University. Series: fisheries 1, 86-91 (2010)

15. Ya.G. Merkulov, I.A. Markov, Modern fisheries and environmental problems of the Azov-black sea region: Proceedings of the IX International scientific and practical conference, 124-130 (2017)

16. A.N. Tumenov, N.H. Sergeliev, B.T. Sariev, S.S. Bakiev, News of science of Kazakhstan 4(130), 125-134 (2016)

17. A.S. Safronov, I.V. Burlachenko, K.V. Dudin, K.V. Sukhova, Mat. of intl. Conf. "Current state and prospects of aquaculture development in the Caspian region", 128133 (2016)

18. M.S. Chebanov, E.V. Galich, Guidelines for artificial reproduction of sturgeon: FAO Technical report on fisheries (2011) http://www.fao.org/3/a-i2144r.pdf

19. M.A. Shcherbina, I.V. Burlachenko, A.V. Myshkin, K.V. Sukhover, A.S. Safronov, O.A. Bondarenko, V.S. Grigoriev, Proceedings of VNIRO 175, 175-190 (2019)

20. G.F. Metallov, E.N. Ponomareva, V.A. Grigoriev, A.V. Dubovskaya, P.P. Geraskin, O.A. Leina, M.N. Sorokina Fish industry 4, 117-131 (2018)

21. G.F. Metallov, E.N. Ponomareva, M.N. Sorokina, V.A. Grigoriev, A.A. Korchunov, Reports of Academy of Sciences 478(6), 37-39 (2018)

22. E.A. Melchenkov, T.A. Kanideva, E.A. Vorobyov, A.A. Archibasov, Fish farming and fisheries 9, 36-41 (2019)

23. O.P. Filippova, S.E. Zuevsky, Prospects for growing a hybrid of Russian sturgeon with Siberian sturgeon in Russia, https: //aquafeed.ru/node/68 